\title{
Estimation of Metformin in Bulk Drug and in Formulation by HPTLC
}

\section{Shweta Havele and Sunil Dhaneshwar*}

Research and Development Centre in Pharmaceutical Sciences and Applied Chemistry, Poona College of Pharmacy, Bharati Vidyapeeth University, Erandwane, Pune411038, India

\begin{abstract}
A simple and sensitive, HPTLC method has been developed for the quantitative estimation of metformin in its single component tablet formulation. Metformin was chromatographed on silica Gel $60 \mathrm{~F}_{25}$ TLC plate using ammonium sulfate (0.5\%): 2-propanol: methanol in the ratio of 8.0:1.6:1.6 $(\mathrm{v} / \mathrm{v} / \mathrm{v})$ as mobile phase. Metformin showed $R_{\mathrm{f}}$ value of $0.50 \pm 0.03$ was scanned at $238 \mathrm{~nm}$ using Camag TLC Scanner 3. The linear regression data for the calibration plot showed a good relationship with $r=0.999$. The method was validated for precision and recovery. The limits of detection and quantification were 95 and $200 \mathrm{ng} / \mathrm{spot}$ respectively. The developed method was successfully used for the assay of metformin tablet formulations. The method is simple, sensitive and precise; it can be used for the routine quality control testing of marketed formulations.
\end{abstract}

Keywords: Thin layer chromatography; Pharmaceutical analysis; Antidiabetic drug; Metformin; Tablet; Bulk drug

\section{Introduction}

Metformin (Metformin $\mathrm{HCl}, \mathrm{N}, \mathrm{N}$-dimethylimidodicarbonimidic diamide hydrochloride, MET, Figure 1) [1] is an oral antidiabetic drug [2]. Metformin hydrochloride is formulated as tablet dosage forms. This drug was approved by the FDA in December 1994 and has been the only clinically available drug that can significantly improve insulin sensitivity in patients that suffer from Diabetes type II (non-insulin dependent). Typically Metformin reduces basal and postprandial hyperglycemia by about $20.5 \%$ in more than $90 \%$ of the patients. Determination of MET in plasma by various analytical methods like HPLC MS or UV detector [3-11], in formulation [12] multicomponent system, HPLC [13,14]. Several other HPLC methods were also developed for the determination of metformin hydrochloride. But these methods are sophisticated, expensive and time consuming as compared to simple HPTLC method. There is a need for a simple, rapid, cost effective and reproducible method for assay of MET in its dosage forms. Therefore, it was thought of interest to develop simple, rapid, accurate, specific and precise HPTLC method for the analysis of MET in its tablet formulation. The objective of the current work is, therefore, to develop a simple HPTLC method for analysis of metformin hydrochloride in tablet formulations.

\section{Experimental}

\section{Materials}

MET working standard was a generous gift from Ranbaxy, Indore, India. Silica gel $60 \mathrm{~F}_{254}$ TLC plates $(10 \times 10 \mathrm{~cm}$, layer thickness $0.2 \mathrm{~mm}$, E. Merck, Darmstadt, Germany) were used as a stationary phase. All chemicals and reagents used were of analytical grade and were purchased from Merck Chemicals, India. Glycomet containing 500 mg of MET were purchased from USV limited, Biciphage containing $850 \mathrm{mg}$ MET were purchased from Biochem and Bigomet containing $250 \mathrm{mg}$ of MET were purchased from Genetica (Aristo).

\section{Instrumentation}

The HPTLC system consisted of a Camag Linomat 5 semi-automatic spotting device (Camag, Muttenz, Switzerland), a Camag twin-trough chamber $(10 \mathrm{~cm} \times 10 \mathrm{~cm})$, Camag winCATS software 1.4.4.6337 and a $100 \mu \mathrm{l}$ Hamilton syringe. Sample application was done on precoated silica gel $60 \mathrm{~F}_{254}$ TLC plates $(10 \mathrm{~cm} \times 10 \mathrm{~cm})$. TLC plates were prewashed with methanol and activated at $80^{\circ} \mathrm{C}$ for 5 min prior to the sample application. Densitometric analysis was carried out utilizing Camag TLC scanner 3.

\section{Preparation of standard solutions}

A stock solution of MET was prepared by dissolving $100 \mathrm{mg}$ in $100 \mathrm{ml}$ methanol $(1000 \mu \mathrm{g} / \mathrm{ml})$. Further standard solutions were prepared by dilution of the stock solution with methanol to reach a concentration range $200-1000 \mathrm{ng} / \mathrm{spot}$.

\section{Sample preparation}

Three brands of tablets Glycomet of (USV limited), Bigomet (Genetica (Aristo)) and Biciphage of (Biochem Pharmaceuticals) were selected. Twenty tablets were weighed and the average weight was calculated. The tablets were then powdered and an amount equivalent to one tablet was dissolved in $50 \mathrm{ml}$ methanol. To ensure complete extraction of the drug it was sonicated for $45 \mathrm{~min}$. This solution was filtered through a Whatman no. 41 paper.<smiles>CNC(=N)NC(=N)N</smiles>

Figure 1: Chemical structure of Metformin.

*Corresponding author: Sunil Dhaneshwar, Research and Development Centre in Pharmaceutical Sciences and Applied Chemistry, Poona College of Pharmacy, Bharati Vidyapeeth University, Erandwane, Pune - 411038, India, E-mail: sunil. dhaneshwar@gmail.com

Received October 02, 2010; Accepted October 25, 2010; Published October 27 2010

Citation: Havele S, Dhaneshwar S (2010) Estimation of Metformin in Bulk Drug and in Formulation by HPTLC. J Nanomedic Nanotechnolo 1: 102. doi:10.4172/21577439.1000102

Copyright: ( 2010 Havele S, et al. This is an open-access article distributed under the terms of the Creative Commons Attribution License, which permits unrestricted use, distribution, and reproduction in any medium, provided the original author and source are credited. 


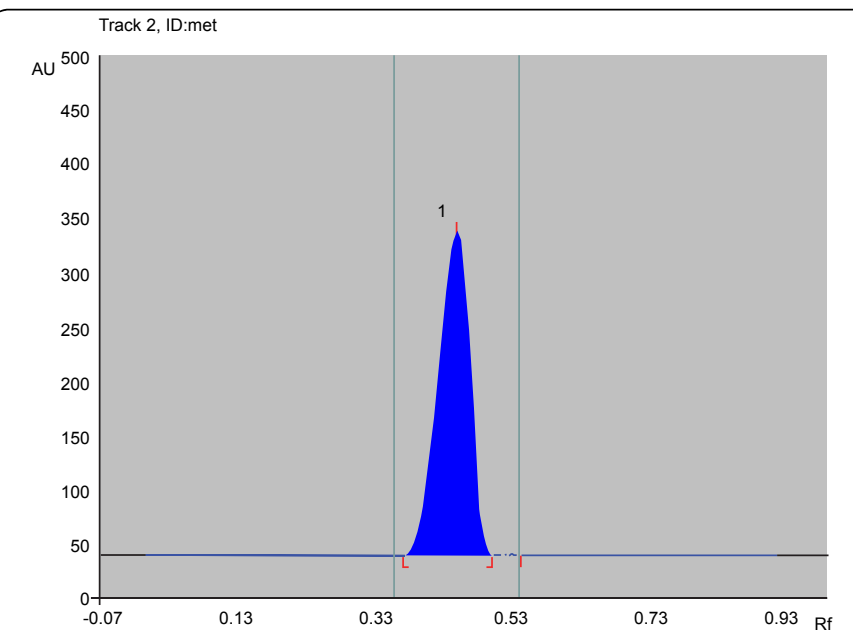

Figure 2: Densitogram of standard metformin $(2000 \mathrm{ng} / \mathrm{spot})$; peak $1\left(\mathrm{R}_{\mathrm{f}}\right.$ : $0.50 \pm 0.03)$. Ammonium sulphate: 2-propanol:methanol (8.0:1.6:1.6 (v/v/v).

\begin{tabular}{|l|l|l|l|}
\hline Linearity (ng/spot) & $\mathrm{r} \pm$ S.D. & Slope \pm S.D. & Intercept \pm S.D. \\
\hline $200-1000$ & $0.999 \pm 0.09$ & $16.73 \pm 1.02$ & $3.962 \pm 0.8$ \\
\hline an $=6$
\end{tabular}

Table 1: Linear regression data for the calibration curves ${ }^{a}$.

\begin{tabular}{|l|l|l|l|}
\hline \multicolumn{2}{|l|}{ Inter-day precision } & Intra-day precision \\
\hline S.D of areas. & \% R.S.D. & S.D of areas. & \% R.S.D. \\
\hline 1.04 & 1.28 & 1.89 & 1.91 \\
\hline
\end{tabular}

${ }^{a} \mathrm{n}=6$, Average of three concentrations $200,600,1000 \mathrm{ng} / \mathrm{spot}$

Table 2: Intra and inter day precision of HPTLC methoda

\begin{tabular}{|l|l|l|}
\hline Parameter & $\begin{array}{l}\text { SD of peak } \\
\text { area }\end{array}$ & $\%$ RSD \\
\hline Mobile phase composition & 0.90 & 1.01 \\
\hline Amount of mobile phase & 1.60 & 1.89 \\
\hline Temperature & 0.60 & 0.90 \\
\hline Relative humidity & 1.26 & 1.81 \\
\hline Plate pretreatment & 0.79 & 0.08 \\
\hline Time from spotting to chromatography & 1.10 & 0.91 \\
\hline Time from chromatography to scanning & 0.08 & 0.05 \\
\hline
\end{tabular}

${ }^{a} n=6$, Average of three concentrations $200,600,1000 \mathrm{ng} / \mathrm{spot}$

Table 3: Robustness testinga ${ }^{a}$.

\section{HPTLC method}

In the proposed HPTLC method, the samples were streaked on the precoated TLC plates in the form of a narrow band $6 \mathrm{~mm}$ in length, $10 \mathrm{~mm}$ from the bottom and margin and $10 \mathrm{~mm}$ apart at a constant flow rate of $150 \mathrm{nl} / \mathrm{s}$ by using a nitrogen aspirator. A Camag Twin Trough Chamber was saturated for $20 \mathrm{~min}$ at room temperature $\left(25 \pm 2{ }^{\circ} \mathrm{C}\right)$ with the mobile phase containing a mixture of ammonium sulfate (0.5\%): 2-propanol: methanol in the ratio of 8:1.6:1.6 (v/v/v). After chamber saturation, the plates were developed to a distance of $80 \mathrm{~mm}$ and then dried in hot air. Densitometric analysis was carried out using a Camag TLC Scanner 3 (Camag) in the absorbance mode at $238 \mathrm{~nm}$ for all measurements. The slit dimension was kept at $5.0 \mathrm{~mm} \times 0.45 \mathrm{~mm}$ and a scanning speed of $20 \mathrm{~mm} / \mathrm{s}$ was employed. MET was detected at $R_{f}$ of $0.5 \pm 0.03$. The chromatograms were integrated using win CATS evaluation software (Version 1.1.3.0).

\section{Calibration plots}

A stock solution of MET $(1000 \mu \mathrm{g} / \mathrm{ml})$ was prepared in methanol. Calibration curves were prepared over a concentration range of 200-
$1000 \mathrm{ng} / \mathrm{spot}$ for MET. These solutions were applied to plates, which were then developed and scanned as described above. The data of area under the peak versus drug concentration (ng/spot) were subjected to regression analysis to calculate the regression equations and correlation coefficients.

\section{Analysis of MET formulations}

Twenty tablets of each brands were weighed their average weight calculated, tablet triturated finely powdered and the powder equivalent to containing $500 \mathrm{mg}, 850 \mathrm{mg}$ and $250 \mathrm{mg}$ of MET from Glycomet, Biciphage and Bigomet respectively and dissolved in $50 \mathrm{ml}$ of methanol. The solution was sonicated for $45 \mathrm{~min}$ and then filtered through Whatman filter paper No. 41. The residue was washed thoroughly with methanol. The filtrate and washings were combined. Each of these solutions $(1 \mu \mathrm{l})$ were spotted on plates and analyzed for MET in the same way as described earlier.

\section{Method validation}

Quantitation: The limit of detection (LOD) was calculated as three times the noise level and limit of quantification (LOQ) was calculated as ten times the noise level.

Accuracy: Recovery studies were carried out to check the accuracy of the method. Recovery experiments were performed by adding three different amounts of MET i.e., 80, 100 and $120 \%$ of the labeled amount of MET analyzed from the MET formulations and the resultant were reanalyzed $(n=6)$.

Precision: Different amounts of MET covering the low, medium and higher ranges of the calibration curve were spotted on the TLC plate for determining intra-day and inter-day precision (over a period of 7 days). These spots were analyzed $(n=6)$ by using the above described HPTLC method.

\section{Results and Discussion}

\section{Chromatography}

In this study, the quantitative HPTLC method was developed for the estimation of MET in tablets. The solvent system comprising of ammonium sulfate (0.5\%):2-propanol: methanol (8:1.6:1.6 v/v/v) could resolve MET spot with better peak shape. It also offered optimum migration $\left(\mathrm{R}_{\mathrm{f}}=0.5 \pm 0.03\right)$ (Figure 2$)$ and resolution of MET from other excipients used in various MET formulations. Chamber saturation time was optimized to $30 \mathrm{~min}$ in order to get distinct bands of MET. The analytical wavelength, $238 \mathrm{~nm}$, was chosen on the basis of the absorption spectrum recorded in the range $200-800 \mathrm{~nm}$.

\section{Validation of the method}

Linearity: Linearity for MET was observed in the range of 200-1000 ng/spot with a correlation coefficient of 0.999 and the linear regression equation was $y=3.962 x+16.73$ (Table 1 ).

Precision: The repeatability of sample application and measurement of peak area were expressed in terms of \% RSD and found to be 1.82 and 1.51 respectively. The results shown in Table 2 revealed intra- and inter-day variation of MET at three different concentration levels $200,600,1000 \mathrm{ng} / \mathrm{spot}$. The \% RSD for within and day-to-day analysis was found to be $<2 \%$.

Robustness of the method: The standard deviation of peak area was calculated for each parameter and \% R.S.D. was found to be less than $2 \%$. The low values of \% R.S.D as shown in Table 3 indicated robustness of the method. 
Citation: Havele S, Dhaneshwar S (2010) Estimation of Metformin in Bulk Drug and in Formulation by HPTLC. J Nanomedic Nanotechnolo 1: 102. doi:10.4172/2157-7439.1000102

Page 3 of 3

\begin{tabular}{|l|l|l|l|}
\hline Formulation & Label Claim (mg) & Drug Content (\%) & \% R.S.D. \\
\hline Glycomet & 500 & 99.82 & 0.98 \\
\hline Biciphage & 850 & 101.0 & 1.30 \\
\hline Bigomet & 250 & 100.24 & 0.36 \\
\hline
\end{tabular}

Table 4: Applicability of the HPTLC method for the analysis of the pharmaceutical formulations.

\begin{tabular}{|l|l|l|l|l|}
\hline \multirow{3}{*}{ Formulation } & $\begin{array}{l}\text { Amount of drug } \\
\text { added (\%) }\end{array}$ & $\begin{array}{l}\text { Thereotical } \\
\text { content (ng) }\end{array}$ & $\begin{array}{l}\text { Amount of MET } \\
\text { recovered (ng) } \\
\text { mean }\end{array}$ & \% Recovery \\
\hline \multirow{3}{*}{ Glycomet } & 80 & 18000 & 18018 & 100.10 \\
\cline { 2 - 5 } & 100 & 20000 & 19846 & 99.93 \\
\cline { 2 - 5 } & 120 & 22000 & 21995.6 & 99.98 \\
\hline \multirow{3}{*}{ Biciphage } & 80 & 30600 & 30544.92 & 99.82 \\
\cline { 2 - 5 } & 100 & 34000 & 33874.2 & 99.63 \\
\cline { 2 - 5 } & 120 & 37400 & 37171.86 & 99.39 \\
\hline \multirow{3}{*}{ Bigomet } & 80 & 9000 & 9003.6 & 100.04 \\
\cline { 2 - 5 } & 100 & 10000 & 9997 & 99.97 \\
\cline { 2 - 5 } & 120 & 11000 & 11031.9 & 100.29 \\
\hline
\end{tabular}

an $=6 \quad$ Table 5: Recovery studies ${ }^{\mathrm{a}}$

\begin{tabular}{|l|l|}
\hline Parameter & Data \\
\hline Linearity range & $200-1000 \mathrm{ng} / \mathrm{ml}$ \\
\hline Correlation coefficient & $0.999 \pm 0.09$ \\
\hline Limit of detection & $95 \mathrm{ng} / \mathrm{ml}$ \\
\hline Limit of quantitation & $200 \mathrm{ng} / \mathrm{ml}$ \\
\hline Recovery $(\mathrm{n}=6)$ & 99.82 \\
Glycomet & 101.0 \\
Biciphage & 100.24 \\
Bigomet & \\
\hline $\begin{array}{l}\text { Precision }(\% \text { RSD) } \\
\text { Repeatability of application }\end{array}$ & 1.82 \\
Inter - day $(\mathrm{n}=6)$ & 1.28 \\
Intra - day ( $\mathrm{n}=6)$ & 1.91 \\
\hline Robustness & Robust \\
\hline Specificity & 0.9991 \\
\hline
\end{tabular}

Table 6: Summary of validation parameters.

LOD and LOQ: The signal to noise ratios 3:1 and 10:1 were considered as LOD and LLOQ respectively. The LOD and LLOQ were found to be 95 and $200 \mathrm{ng} / \mathrm{spot}$ respectively.

Specificity: The peak purity of MET was assessed by comparing the spectra of standard at peak start, peak apex and peak end positions of the spot i.e., $r$ (start, middle) $=0.998$ and $r$ (middle, end) $=0.9993$. Good correlation $(r=0.9991)$ was also obtained between standard and sample spectra of MET.

Recovery studies: The proposed method when used for extraction and subsequent estimation of MET from pharmaceutical dosage form after spiking the preanalysed sample with 80,100 and $120 \%$ of label claim of MET afforded recovery of $99-101 \%$ as listed in Table 5. The data of summary of validation parameters are listed in Table 6.

Analysis of MET formulations: A single spot at $R_{f} 0.5$ was observed in the densitogram of the drug samples extracted from tablets. There was no interference from the excipients commonly present in the tablets.

The results, given in Table 4, indicate that the amount of drug in the tablets is within the requirement of $99-101 \%$ of the label claim.

\section{Conclusion}

A new HPTLC method has been developed for the identification and quantification of MET in formulations. The method was found to be simple, sensitive, precise, accurate and specific for estimation and can be conveniently employed for the routine quality control analysis of MET from tablets.

\section{Acknowledgements}

Authors thank the Ranbaxy Pharmaceuticals Ltd., Indore for the gift sample of metformin hydrochloride.

\section{References}

1. Klepser TB, Kelly MW (1997) Metformin hydrochloride: an antihyperglycemic agent. Am J Health System Pharm 54: 893-903.

2. Hitt $E$ (1995) Uses of metformin may extend beyond patients with type 2 diabetes. Drugs 63:1879-1894.

3. Mistri HN, Jangid AG, Shrivastav PS (2007) Liquid chromatography tandem mass spectrometry method for simultaneous determination of antidiabetic drugs metformin and glyburide in human plasma. J Pharm Biomed Anal 45: 97-106.

4. Georgita C, Albu F, David V, Medvedovici AJ (2007) Simultaneous assay of metformin and glibenclamide in human plasma based on extraction-less sample preparation procedure and LC/(APCI)MS. J Chromatogr B Analyt Technol Biomed Life Sci 854: 211-218.

5. Zhang L, Tian Y, Zhang Z, Chen Y (2007) Simultaneous determination of Metformin and rosiglitazone in human plasma by liquid chromatography/ tandem Mass spectrometry with electrospray ionization: application to a pharmacokinetic study. J Chromatogr B Analyt Technol Biomed Life Sci 854: 91-98.

6. Marques MA, Soares Ade S, Pinto OW, Barroso PT, Pinto DP, et al. (2007) Simple and rapid method determination for metformin in human plasma using high performance liquid chromatography tandem mass spectrometry: Application to pharmacokinetic studies. J Chromatogr B Analyt Technol Biomed Life Sci 852: 308-316.

7. Ding CG, Zhou Z, Ge QH, Zhi XJ, Ma LL (2007) Simultaneous determination of metformin and glipizide in human plasma by liquid chromatographytandem mass spectrometry. Biomed Chromatogr 21: 132-138.

8. Aburuz S, Millership J, McElnay J (2005) The development and validation of liquid chromatography method for the simultaneous determination of metformin and glipizide, gliclazide, glibenclamide or glimperide in plasma. $J$ Chromatogr B Analyt Technol Biomed Life Sci 817: 277-286.

9. Koseki N, Kawashita H, Niina M, Nagae Y, Masuda N (2005) Developmen and validation for high selective quantitative determination of metformin in human plasma by cation exchanging with normal-phase LC/MS/MS. J Pharm Biomed Anal 36: 1063-1072.

10. Wang Y, Tang Y, Gu J, Fawcett JP, Bai X (2004) Rapid and sensitive liquid chromatography-tandem mass spectrometric method for the quantitation of metformin in human plasma. J Chromatogr B Analyt Technol Biomed Life Sci 808: 215-219.

11. Heinig K, Bucheli F (2004) Fast liquid chromatographic-tandem mass spectrometric (LC-MS-MS) determination of metformin in plasma samples. J Pharm Biomed Anal 34: 1005-1011.

12. Kar M, Choudhury PK (2009) HPLC method for estimation of metformin hydrochloride in formulated microspheres and tablet dosage form. Indian $J$ Pharm Sci 71: 318-320.

13. Hegazy MA, El-Ghobashy MR, Yehia AM, Mostafa AA (2009) Simultaneous determination of metformin hydrochloride and pioglitazone hydrochloride in binary mixture and in their ternary mixture with pioglitazone acid degradate using spectrophotometric and chemometric methods. Drug Test Anal 1: 339 349 .

14. Chaturvedi PK, Sharma R (2008) Development and Validation of an RP-HPLC Method for Simultaneous Analysis of a Three-Component Tablet Formulation Containing Metformin Hydrochloride, Pioglitazone Hydrochloride and Glibenclamide. Acta Chromatographica 3: 451-461. 